\title{
Parental judgements of infant pain: Importance of perceived cognitive abilities, behavioural cues and contextual cues
}

\author{
Rebecca R Pillai Riddell MA, Melanie A Badali MA, Kenneth D Craig PhD
}

\begin{abstract}
RR Pillai Riddell, MA Badali, KD Craig. Parental judgments of infant pain: Importance of perceived cognitive abilities, behavioural cues and contextual cues. Pain Res Manage 2004;9(2):73-80.
\end{abstract}

BACKGROUND: Despite blatant indications, such as behavioural and contextual cues, infant pain is often undermanaged by adult caretakers. The belief that infants are limited in their abilities to comprehend the meaning of an experience or recall that experience has been used to minimize or deny the need for intervention in this vulnerable population.

OBJECTIVES: This investigation explored parental beliefs regarding the impact of infant cognitive capabilities, behavioural cues and contextual cues to their pain judgments. Particular interest was focused on their beliefs regarding the general cognitive capabilities of infants of different ages.

METHODS: Forty-nine parents viewed videotapes of healthy infants, aged two, four, six, 12 and 18 months, receiving routine immunization injections and provided judgements of the severity of pain on a $100 \mathrm{~mm}$ Visual Analogue Scale. Upon completion of their pain judgements for each of the five age groups (two infants per age group; 10 infants total), parents completed questionnaires regarding their beliefs about the capabilities of infants in that age group and then reported the importance of the various cues utilized to formulate their pain judgements.

RESULTS: Parents attributed substantial pain to infants in all age groups, almost twice the amount they hypothesized an adult undergoing a similar injection would experience. The cues rated as most important for judgements were similar for infants of varying ages. Overall, facial expressions, sounds and body movements were consistently reported to be most important. Parents acknowledged the development of memory and understanding of pain throughout infancy. However, these beliefs were not deemed by parents as important to their pain ratings, nor were their importance ratings directly related to the pain ratings.

CONCLUSION: Parents judged that infants undergoing a routine immunization were experiencing clinically significant levels of pain. However, despite generally acknowledging a developing trajectory for memory and understanding across the five age groups, parents did not indicate that a child's ability to remember and understand pain were essential features of their pain judgements. The results indicated that memory and understanding did not influence parental judgements of infant pain demonstrating the validity of the parents' selfassessments.

Key Words: Infants; Memory; Pain judgement; Parents; Understanding
Jugement des parents devant la douleur des enfants : importance des habiletés cognitives perçues, des signes comportementaux et des signes contextuels

CONTEXTE : Malgré des indices criants, comme des signes comportementaux et des signes contextuels, la douleur chez les enfants en bas âge est souvent négligée par les adultes qui s'en occupent. La croyance selon laquelle les petits enfants n'ont pas les capacités suffisantes pour comprendre une expérience en particulier ou se la rappeler est souvent invoquée pour minimiser, voire nier, la nécessité d'une intervention dans cette population fragile.

OBJECTIF : L'enquête visait à explorer les croyances des parents quant à l'incidence des capacités cognitives des jeunes enfants, des signes comportementaux et des signes contextuels sur leur évaluation de la douleur. Une attention particulière a été portée aux croyances ayant trait aux capacités cognitives générales des enfants de différents âges.

MÉTHODE : Quarante-neuf parents ont regardé des scènes vidéo dans lesquelles des enfants en bonne santé, âgés de 2, 4, 6, 12 et 18 mois, étaient vaccinés par injection et ils ont évalué le degré d'intensité de la douleur sur une échelle visuelle analogue de $100 \mathrm{~mm}$. Une fois qu'ils eurent terminé l'évaluation de la douleur pour chacun des groupes d'âge ( 2 enfants par groupe, soit 10 au total), les parents ont rempli un questionnaire sur leurs croyances relativement aux capacités des enfants dans les différents groupes d'âge; ils ont ensuite indiqué l'importance des divers signes ayant servi à former leur jugement sur l'intensité de la douleur. RÉSULTATS : Les parents ont accordé des cotes très élevées de douleur aux enfants dans tous les groupes d'âge, presque le double de celles qu'ils supposaient pour un adulte subissant la même expérience. Les signes jugés les plus importants pour l'évaluation de la douleur étaient à peu près les mêmes pour tous les enfants, quel que soit leur âge. Dans l'ensemble, ce sont l'expression faciale, les cris et les pleurs ainsi que les mouvements du corps qui ont été considérés comme les plus importants. Les parents ont reconnu l'installation progressive de la mémoire et de la compréhension de la douleur tout au long de la petite enfance. Toutefois, ces croyances n'ont pas été jugées aussi importantes par les parents pour l'évaluation de la douleur, et il n'y avait pas de lien direct entre l'appréciation des croyances et l'évaluation de la douleur.

CONCLUSIONS : Les parents ont estimé que les enfants en bas âge recevant un vaccin par injection éprouvaient un degré élevé de douleur sur le plan clinique. Toutefois, même s'ils ont reconnu en général l'installation progressive de la mémoire et de la compréhension chez les enfants dans les cinq groupes d'âge, les parents n'ont pas indiqué que la capacité des enfants à se rappeler une expérience douloureuse et à la comprendre avait constitué un élément essentiel dans l'évaluation de la douleur. Bref, les résultats montrent que la mémoire et la compréhension n'ont pas modifié le jugement des parents en ce qui concerne l'intensité de la douleur chez les jeunes enfants, prouvant ainsi la validité de l'autoévaluation des parents.

University of British Columbia, Vancouver, British Columbia

Correspondence: Rebecca R Pillai Riddell, Pain Research Laboratory, Department of Psychology, The University of British Columbia,

DT Kenny Building, 2136 West Mall, Vancouver, British Columbia V6T 124. Telephone 604-822-5280, fax 604-822-6923,

e-mail beccap@interchange.ubc.ca 
$E^{v}$ vidence of the undermanagement of infant pain $(1,2)$ highlights the importance not only of research on the nature of an infant's response to tissue damage, but also the examination of factors that influence caregiver assessments of infant pain. Although there has been considerable progress in developing standardized measures of infant pain (3-7), caregivers, especially parents, are typically unschooled in psychometrically validated procedures (8).

\section{FACTORS INFLUENCING PAIN ASSESSMENT}

Research investigating factors important to nurses' judgements of pain identify vocalizations, body movements or posture, and facial expressions as most important (9-17). However, there is a dearth of research examining parents' perceptions of infant pain and the cues they actually use to assess pain.

\section{Beliefs about infant capacity to experience pain}

Convictions that infants are limited in their abilities to comprehend the meaning of an experience or recall that experience have been used to minimize or deny their capacity for pain. Derbyshire (18) contends that newborns do not feel pain because "such a suggestion draws a false parallel between the experience of verbal children and adults and that of the fetus or neonate". Such reservations about the capabilities of infants to experience pain have also led to proposals to qualify infant pain as only 'probable' or 'inferred' (19). These arguments have profound implications. If these capabilities were construed as necessary features of pain, absence of a capacity for comprehension and/or memory would influence how caregivers assess and manage pain. For example, Vertosick (20), a neurosurgeon, recently argued that infant surgical pain would be unimportant because

"in certain select pediatric cases, anesthesiologists may use only drug-induced paralysis. Babies can't remember anything anyway. I had a spinal tap without anesthesia as an infant and I don't recall a thing. I'm sure I screamed bloody murder at the time, but it hasn't affected me otherwise".

Despite this anecdotal report, empirical research strongly suggests a long-term deleterious impact of exposure to noxious experiences during infancy (2,21-25).

Recent decades have seen substantial changes in our understanding of infants' capabilities for painful experience. Most investigators now argue for at least a physiological capacity for nocioception and the distressing sensory and affective qualities of the experience of pain during the neonatal period $(3,18,26)$. Evidence indicates that preterm newborns have the neurobiological systems required to experience pain $(27,28)$ and respond behaviourally in a manner identifiable as signifying pain (29). As well, structures required for long-term memory (eg, hippocampus, amygdala, anterior and mediodorsal thalamic nuclei, and mamillary nuclei) are well developed and functional during the newborn period (21). Furthermore, follow-up studies of infants subjected to intense or repeated episodes of pain indicate long-term changes in both observer global judgements of pain and objective physiological, cognitive and behavioural changes in response to painful procedures during infancy $(2,22-25)$. While previous research has examined the cues health care professionals use to make decisions about infant pain, less attention has been paid to parents who are primarily responsible for infant care outside health care settings. In particular, an examination of parents' perceptions of infant cognitive capabilities and how they may relate to their attributions of pain is of special interest.

The purpose of this study was to examine developmental trends in how parents would assign a general capacity to understand and remember pain to infants of increasing ages, and the relationships between the importance of their attributions of infant cognitive capabilities and judgements of infant pain. Parents viewed videoclips of infants (aged two, four, six, 12 and 18 months) receiving immunizations. Next, they rated the severity of pain experienced and the importance of various infant cognitive beliefs (eg, infants' ability to understand pain, infants' ability to remember pain), behavioural cues (eg, facial expressions, crying, body movements), and contextual cues (eg, the setting the infant was in, the fact that the infant had received a needle) to their judgements.

Based on previous research examining nurses' judgements of infant pain, it was anticipated that parents would rate behaviour cues (eg, facial expressions, crying) as important in their pain reports (9-17). It was further hypothesized that parents who characterized cognitive abilities (eg, remembering, understanding) as important to their judgements of pain severity would attribute less pain to children less capable of these abilities, namely the younger infants. Given that comprehension and understanding increase throughout infancy (30), it was hypothesised that if learning and memory were deemed important determinants of pain judgements, older infants would receive higher pain intensity ratings.

\section{METHODS}

\section{Participants}

Forty-nine parents ( 40 mothers and nine fathers mean $=41.02$ years, $\mathrm{SD}=9.02$ ) were recruited from an interactive, child-oriented science museum (Science World; Vancouver, British Columbia). Interested parents were instructed via on-site posters to go to the study booth, which was set up in a common area of the museum away from the displays.

The judgement portion of the study took place in a closed room, adjacent to the recruitment booth. Children of participating parents remained outside of the judgement room and under the supervision of another research assistant. The children participated in age-appropriate activities designed to teach children about pain and the brain. Remuneration was a discount coupon from a popular food vendor on the premises.

The self-identified ethnic composition of the sample included 43 white individuals, one black individual and three Asians (two participants denoted "other" but offered no additional information). Parents' educational backgrounds varied substantially (high school or less, $n=8$; trade school, $n=9$; some university, $n=7$; undergraduate degree, $\mathrm{n}=12$; graduate school or other professional programs, $n=13)$. Parents had an average of 2.13 children $(S D=1.42)$ and generally represented two parent families (two parent family, $\mathrm{n}=38$; one parent family, $\mathrm{n}=7$; other, $\mathrm{n}=5$ ). To assess parents' background in infant development and care, they were asked two questions: 1) "Have you taken any courses in infant development and care and, if so, how many?" and 2) "Does your occupation directly or indirectly relate to infant development and care?" Twenty parents had completed at least one course in infant development or care (mean number of courses $=0.452$, range $=0-3$ courses). Most 
parents identified an occupation unrelated to infants $(n=38)$, while some parents were employed in positions that either directly $(n=9)$ or indirectly $(n=2)$ related to infants.

\section{Materials}

Video stimuli: Videoclips of infants (aged two, four, six, 12 and 18 months) undergoing a painful injection were randomly selected from 75 recordings produced from a study of healthy infants receiving routine immunization at a family health unit (31). Random selection was achieved by assigning each clip a number and selecting these numbers randomly out of a bowl. Videoclips were excluded if parental facial expressions were notably visible to eliminate these as a source of influence on judgements. Given that all infants had been administered the same noxious stimulus, no other criteria was initially used when creating the judgement tapes.

Seventy-five per cent of the randomly selected infants were white, while the remainder were of varied Asian backgrounds (eg, East Indian, Japanese, Chinese). Each videoclip displayed an infant for 10 seconds, starting with the moment of skin puncture. The infant's age appeared in the upper right hand corner of the screen for the duration of the clip. A blank blue screen was displayed for 10 seconds between clips. Given strict time limits dictated by the science museum, pilot testing had determined that each participant would be able to judge 10 infants (two per age group) in the allotted time. Because only two infants could be judged from each age group, three unique sets of 10 stimulus infants (each set had two different infants from the five different age groups) were used to increase the overall number of infants being judged in each age group. Each participant would view one of the three sets and subsequent between set comparisons (refer to "Comparability of infant sets" in the "Results" section) were planned to justify using a mean pain rating for each of the age groups. Videoclips of infants within each age group were presented in a counterbalanced order to control for potential serial order effects of age on judgements (32).

Judgement questionnaires: Visual Analogue Scale: Parents rated the severity of each child's pain by placing a mark on a $100 \mathrm{~mm}$ Visual Analogue Scale (VAS), anchored by "No Pain" and "Worst Pain Possible." The VAS is considered a sensitive and reliable measure of the intensity of pain (6). It has been shown to be quick to use and easy to understand even if one's mother tongue is not English (33). High convergent and divergent validity, and adequate test-retest and interrater reliability of this measure are well established in the area of pain (34-37). Previous research has demonstrated convergent validity between infant pain judgements using a VAS and other well-established behavioural indicators of pain such as pain cry, facial expressions and stiff posturing (38-40).

To elicit parental beliefs about infants' cognitive capabilities in experiencing pain and the cues that were important to their pain judgements, two questionnaires were created with items based on the infant judgement literature $(9,11,13$ $15,41,42)$. A review of the literature revealed no instruments that quantitatively examined either the judges' beliefs about an infant in pain's developmental capabilities or the differential importance of cues used to formulate infant pain judgements. Two questionnaires were developed (Pillai Riddell, 2003, unpublished dissertation), one to assess development beliefs (Infant Capabilities Questionnaire) and the other to determine the relative importance of different cues used to attribute pain to the infants (Importance of Cues Questionnaire). They were initially pilot tested on a small sample of university students (three graduate students and four undergraduate students; none of the students were affiliated with pain research) to determine ease of use and comprehension of task demands. Given the education level of the sample ( $84 \%$ had more than a high school diploma), this pilot sample appears reasonable. Moreover, during data collection, research assistants were specifically instructed to take notes on any difficulties regarding the study protocol, including participant comprehension of the measures. No systematic difficulties in using these exploratory measures were noted.

Infant Capabilities Questionnaire: This questionnaire provided 10 statements about infants' capabilities for pain experience with three alternative responses (true, false and unsure) per statement. Instructions indicated, "We are interested in your reasons for giving the pain estimate you did for this age group," and described the response format. Two statements were of particular interest in the present study: children of this age group understand pain and a child in this age group cannot remember pain. Eight other statements were included on the measure and served the purpose of avoiding bias involved with asking parents solely about cognitive cues. Examples of other statements on the questionnaire are "The body movements of a child in this age group can indicate how much pain they are feeling" and "Children of this age group can make sounds to indicate how much pain they are feeling".

Importance of Cues Questionnaire: Using a scale ranging from zero (not important) to 10 (extremely important), parents were asked to rate the importance of 12 infant judgement cues that were reviewed in the infant pain literature to date. Two cues concerned the perceived roles of cognitive capabilities in the experience of pain, namely "the infants' capacity to understand pain" and "the infants' capacity to remember pain". The other cues on the questionnaire were "the infants' age", "the infants' sounds", "the infants' facial expression", "the infants' sizes", "the infants were in a medical setting", "the infants had just received a needle", "the infants' mood", "the infants' body movements", "the infants were healthy" and "the infants' capacity to focus on their surroundings". Judges were provided two blank spaces to write in and rate other cues that they felt were important to their pain judgements but that were not included on the questionnaire. Using these two measures researchers aimed to differentiate between the judges' beliefs about infants' pain and the importance of those beliefs to their actual pain judgements.

\section{Procedure}

Ethical approval was obtained from the University of British Columbia's Human Subjects Review Board and informed consent was obtained from participants. Participation required the following: 1) Background: Parents completed a demographics
questionnaire;

2) Training: Parents judged a sample infant to familiarize them with the procedure (no age revealed; all parents watched the same sample video clip); 
TABLE 1

Mean Visual Analogue Scale (VAS) scores for the five age groups and the adult estimate

\begin{tabular}{lcc}
\hline Age group & Mean VAS & SD \\
\hline 2 month $^{1}$ & 59.74 & 19.67 \\
4 month $^{1}$ & 63.40 & 19.94 \\
6 month $^{1}$ & 65.42 & 21.25 \\
12 month $^{1}$ & 64.47 & 20.37 \\
18 month $^{1}$ & 65.63 & 18.69 \\
Adult estimate $^{2}$ & 33.85 & 25.41 \\
\hline
\end{tabular}

1,2Different superscripts indicate difference at $P<0.05$

TABLE 2

Frequency of responses to the statement "Children of this age group understand pain" (n [\%])

\begin{tabular}{lcll}
\hline Age group & False & Unsure & True \\
\hline 2 months & $20(40.8)$ & $8(16.3)$ & $20(40.8)$ \\
4 months & $19(38.8)$ & $4(8.2)$ & $26(53.1)$ \\
6 months & $17(34.7)$ & $7(14.3)$ & $25(51.0)$ \\
12 months & $8(16.3)$ & $6(12.2)$ & $35(71.4)$ \\
18 months & $4(8.2)$ & $1(2.0)$ & $44(89.8)$ \\
\hline
\end{tabular}

3) View infant pain stimuli: Parents viewed 10 second videoclips of infants receiving an immunization injection;

4) Pain Rating for each infant: Parents rated the severity of each child's pain using the VAS. Parents completed each pain rating directly after viewing each clip;

5) Judgement questionnaires for each age group: After viewing the two clips at each age group (two, four, six, 12 and 18 months), parents completed the Infant Capabilities Questionnaire and the Importance of Cues Questionnaire. Thus, the questionnaires were filled out each time a parent had viewed all the infants from a particular age group; and

6) Hypothetical Adult Judgement: After judging all 10 infants, parents were asked to hypothesize how much pain an adult would experience if they received a similar noxious stimulus. The judgement sheet that bore the adult VAS judgement was presented to parents in a format identical to the sheets used for the infant judgements. The only difference in the sheets was that parents were asked "To place a mark on the line to show how much pain you estimate an adult would experience if they received the same needle as the infants they had just watched" as opposed to being asked "To place a mark on the line to show how much pain you estimate the infant you just viewed was experiencing".

\section{Comparability of infant sets}

\section{RESULTS}

Mean VAS scores for the two infants at each age group were calculated for each judge. To ensure pain ratings were not impacted by the randomly selected group of infants the parents watched, differences in pain ratings between the three unique groups of randomly selected infants were examined
TABLE 3

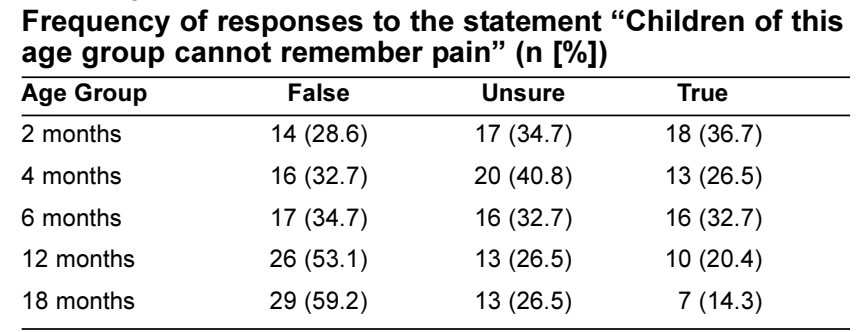

using one-way Analysis of Variance (ANOVA) for each of the five age groups. Significant group differences were found for the four month old, $\mathrm{F}(2,67)=4.477, \mathrm{P}>0.001$, six month old $(\mathrm{F}[2,69]=58.549, \mathrm{P}<0.001)$, and 12 month old groups $(F[2,69]=9.280, P<0.001)$. Post hoc analyses using the Student Newman Keuls method revealed in all cases (four, six and 12 month old groups) that it was the same set of clips that significantly differed from the other two sets. On reviewing each set of clips, it was noted that the set of clips that resulted in the significantly different ratings was the only set of clips that included behaviourally nonresponsive children. Given that the ages of the 'stoic' children corresponded to the significant differences determined in the aforementioned post-hoc analyses, data from this group were excluded from subsequent analyses. Thus, of an original 76 parents participating in the judgement study, one set of 27 parents was excluded due to the unexpected effect of randomly selecting 'stoic' infants for judgement. One-way ANOVA analyses indicated that the excluded group did not differ from the other two groups in terms of age, level of education, number of infant development courses taken, number of months working with infants, or their VAS judgement of the sample infant. The remaining data on the two groups of videoclips were collapsed to provide a single group for all subsequent analyses.

Parent perception of age variation in infant pain severity A one-way repeated measures ANOVA was conducted to determine if parent judgements of infant pain using VAS scores differed among the age groups and the hypothetical adult (Table 1$)$. As sphericity was violated $\left(\chi^{2}[14]=54.075\right.$, $\mathrm{P}<0.05)$, a Greenhouse-Geisser correction was applied to the degrees of freedom and the appropriate error terms were used in post-hoc analyses. Significant results were obtained across age groups and the adult group, $\mathrm{F}(3.027,115.013)=33.180$, $\mathrm{P}>0.001$. Subsequent Tukey post-hoc analyses $(\mathrm{P}<0.05)$ determined that the hypothesized adult VAS score was significantly lower than the VAS scores of all five infant age groups, but no differences existed among mean pain ratings for the five age groups.

Parental beliefs about infant capacities and pain judgements The proportion of parents choosing "True", "False" and "Unsure" to the two "capability' statements ("Children of this age group understand pain" and "A child in this age group cannot remember pain") were examined (Tables 2 and 3).

Attributions of understanding pain: To investigate the relationship between pain ratings and parental beliefs concerning an infants' ability to understand pain, one-way ANOVAs were conducted for each of the five age groups using the parents' 
TABLE 4

\section{Most highly rated judgement cues (in terms of importance) by age group ${ }^{1}$}

\begin{tabular}{|c|c|c|}
\hline Age group & an rating & SD \\
\hline \multicolumn{3}{|l|}{2 month olds } \\
\hline 1. The infants' sounds (sounds) & 8.63 & 2.13 \\
\hline 2. The infants' facial expressions (facial) & 8.27 & 2.42 \\
\hline 3. The infants' body movements (body) & 7.55 & 2.83 \\
\hline $\begin{array}{l}\text { 4. The infants had just received a needle } \\
\text { (needle) }\end{array}$ & 6.53 & 3.45 \\
\hline 5. The infants' age (age) & 4.42 & 4.07 \\
\hline \multicolumn{3}{|l|}{4 month olds } \\
\hline 1. Facial & 8.90 & 1.33 \\
\hline 2. Sounds & 8.61 & 1.98 \\
\hline 3. Body & 8.24 & 2.29 \\
\hline 4. Needle & 6.78 & 3.32 \\
\hline 5. The infants' mood (mood) & 4.94 & 3.69 \\
\hline \multicolumn{3}{|l|}{6 month olds } \\
\hline 1. Facial & 8.75 & 1.57 \\
\hline 2. Sounds & 8.65 & 1.94 \\
\hline 3. Body & 7.82 & 2.84 \\
\hline 4. Needle & 6.73 & 3.47 \\
\hline 5. Mood & 5.00 & 3.77 \\
\hline \multicolumn{3}{|l|}{12 month olds } \\
\hline 1. Facial & 8.90 & 1.43 \\
\hline 2. Sounds & 8.73 & 1.89 \\
\hline 3. Body & 8.67 & 1.49 \\
\hline 4. Needle & 6.86 & 3.64 \\
\hline 5. Mood & 5.76 & 3.54 \\
\hline \multicolumn{3}{|l|}{18 month olds } \\
\hline 1. Facial & 8.63 & 1.85 \\
\hline 2. Sounds & 8.55 & 1.82 \\
\hline 3. Body & 7.96 & 2.35 \\
\hline 4. Needle & 6.86 & 3.31 \\
\hline 5. Mood & 6.08 & 3.48 \\
\hline
\end{tabular}

${ }^{1}$ Ratings were made on a zero (Not Important) to 10 (Extremely Important) scale

responses of true, false and unsure as a grouping factor and the VAS pain ratings as the dependent variable. For the two, four, six and 12 month old age groups, Levene's test for Homogeneity of Variance (HOV) was not violated. These four $F$ values were non-significant, indicating that parental pain ratings did not differ according to whether they believed an infant was capable of understanding pain. No analysis could be conducted with the 18-month-old group due to HOV violations resulting from the overwhelming majority of parents (89.8\%, Table 2) believing this statement to be "true".

Attributions of remembering pain: To investigate the relationship between pain ratings and parental beliefs concerning an infants' ability to remember pain, one-way ANOVAs were again conducted for each of the five age groups using the parents' responses of true, false and unsure as a grouping factor and the VAS pain ratings as the dependent variable. For the two, 12 and 18 month old age groups, Levene's test for HOV was not violated. All three $\mathrm{F}$ values were nonsignificant, indicating that parental pain ratings did not differ according to whether they believed an infant was capable of remembering pain. No further analyses could be conducted with the four and six month old groups due to HOV violations caused by
TABLE 5

Means and standard deviations of cognitive abilities importance scores ${ }^{1}$

\begin{tabular}{|c|c|c|c|c|}
\hline \multirow[b]{2}{*}{ Age group } & \multicolumn{2}{|c|}{$\begin{array}{c}\text { Infants ability to } \\
\text { understand }\end{array}$} & \multicolumn{2}{|c|}{$\begin{array}{l}\text { Infants ability to } \\
\text { remember }\end{array}$} \\
\hline & Mean & SD & Mean & SD \\
\hline 2 month olds & 3.327 & 3.448 & 2.959 & 3.253 \\
\hline 4 month olds & 3.408 & 3.129 & 3.082 & 2.943 \\
\hline 6 month olds & 3.674 & 3.138 & 3.122 & 3.093 \\
\hline 12 month olds & 4.898 & 3.151 & 4.450 & 3.266 \\
\hline 18 month olds & 5.653 & 3.388 & 5.306 & 3.447 \\
\hline
\end{tabular}

${ }^{1}$ Ratings were made on a zero (Not Important) to 10 (Extremely Important) scale

large differences in the variance estimates between the cells (the number of subjects within the cells were generally proportional to each other).

Parental self-report of cues important to their pain judgements

Most highly rated cues: Parents' importance ratings of the 12 cues provided were examined. When given the option, only one of the forty-nine parents proposed an additional source of information ("looked hungry"), suggesting the list of 12 cues was comprehensive. Table 4 lists the five most important cues (as indicated by the parental importance ratings) for each of the five age groups. At all ages, albeit in slightly different orders, the following were rated as the most important cues to parents: sounds, facial expressions and body movements. Other cues rated as important were "the infants had just received a needle," "the infants' age" and "the infants' mood." Notably, neither the "the infant's capacity to understand pain" nor "the infant's capacity to remember pain" were among the top five judgement cues, regardless of age group (Table 5).

Relationship between importance ratings and pain judgements across the different age groups: To determine if a relationship existed between pain ratings and the importance ratings for the memory and the understanding cues, bivariate correlations were run for each cognitive cue and the pain rating across all five age groups (10 correlations in total). None of these 10 correlations approached significance $(\mathrm{P}>0.20)$.

\section{DISCUSSION}

Parents had little difficulty identifying significant pain in even the youngest age group and recognized that the cognitive capacities of understanding and memory for pain unfolded with increasing age. But they did not report these cognitive capabilities to be important factors in their pain judgements. The following examines these features of the parents' judgements of infants' pain. The discussion only pertains to judgements of infants that actively responded to the needle stimulus (ie, demonstrated facial reactivity, cry and body movements), as the sample of parents who judged the 'stoic' babies were not included for analysis.

\section{Comparison of pain ratings}

The parents identified comparably strong levels of pain across the range of infants studied (two to 18 months old), providing an overall mean estimate (eg, across all five age groups) of $63.70 \mathrm{~mm}$ on the $100 \mathrm{~mm}$ VAS. Mean ratings of pain did not differ across the infant age groups sampled. In addition, the parents believed that adults exposed to the needle injection 
would experience relatively lower levels of painful distress (33.85 mm). According to Collins et al (43), a VAS score greater than $30 \mathrm{~mm}$ represents clinically significant pain. The substantially greater attribution of pain to the infants suggested that parents believe that throughout infancy, invasive events are more painful than would be the case for adults undergoing the same experience. This result must be interpreted with caution given the different methodology used to obtain pain judgements for the infants (based on videoclips of infants) versus the adult (based on a hypothetical adult).

Looking at comparative judgements made by health professionals, Schecter and Allen (44) asked physicians "at what age do you believe children experience pain similar to adults". Only $22 \%$ of surgeons, $38 \%$ of family practitioners and $56 \%$ of pediatricians believed the answer was "birth". Even at two years of age, only $54 \%$ of surgeons, $70 \%$ of family practitioners and $84 \%$ of pediatricians believed that infants were capable of experiencing pain like adults (percentages extrapolated from graphs within the original article). The article suggested that the physicians believed infants experience limited pain, but this assertion may be spurious. The physicians may have believed infants experience more pain than adults, but of a qualitatively different nature, in accordance with the proposition that cognitive capabilities slowly emerge early in life.

McLaughlin et al (45) focused on pain severity in a study of physicians who identified themselves with a speciality of neonatal-perinatal medicine and had completed a fellowship in neonatology. When asked to respond to the statement that "neonates experience pain to a lesser degree than adults", only $32.2 \%$ of these experts "strongly disagreed" with this statement (choosing a seven on a seven point scale, where $1=$ strongly agree and $7=$ strongly disagree), while $67.8 \%$ of the sample expressed agreement with this statement to a varying degree. Another study by Porter et al (46), examined the beliefs of physicians and nurses who worked in nurseries in a large metropolitan area. The sample was asked to compare the intensity of infant versus adult pain. Fifty-nine per cent of physicians and $64 \%$ of nurses believed that infants were able to feel the same severity of pain as adults, while roughly $27 \%$ believed infants feel more pain and only 10\% believed infants feel less pain than adults. As aforementioned, the parents in the current study estimated that an adult's pain rating in response to an immunization needle was roughly $34 \mathrm{~mm}$. Examining the frequency distribution of their mean infant pain ratings revealed that $94 \%$ of these parents attributed a higher pain rating to the infants than to the hypothesized adult. This suggests that in comparison to health professionals, parents (that resemble the current sample) hold less variable beliefs about infant pain and that their modal belief regarding adult-infant comparisons is that infants would experience more pain.

In the absence of an absolute index of the severity of pain actually experienced, both parental and health professional estimates can be seen as informed guesses. Relative to health professionals, parents would seem to confront a more emotionally distressing, ambiguous and challenging task, given their personal investment in their children and, most often, a lack of experience and technical knowledge. These factors would seem to argue for biases toward overestimating rather than underestimating pain. In contrast, by virtue of their exposure to pain on a regular basis, an appreciation of the technologies for the control of pain and the availability of antagonists if analgesics prove dangerous, and systemic beliefs concerning the risks of using potent analgesics with children and infants, health care practitioners would be disposed to estimates of pain that were less severe.

\section{Memory and understanding as features of infant pain experience}

An initial caveat should be offered regarding the interpretation of the questionnaires designed to better understand how the parents made their pain judgements. Given the exploratory nature of work in the area exploring what caregivers believe about infants in pain, two measures (the Importance of Cues Questionnaire and the Infants Capabilities Questionnaire) were created based on relevant infant judgement studies found in peer-reviewed journals. Specifically regarding the Importance of Cues Questionnaire, when given the opportunity, almost all the parents (48 of 49 parents[98\%]) did not exercise the option to write in any additional cues, suggesting that the provided cues were comprehensive. Furthermore, basic content validity has also been demonstrated. The low importance ratings of "the infants' ability to remember" and "the infants' ability to understand" the pain experience is validated by the lack of relationship between pain ratings and importance ratings of those cues across all age groups. A limited level of test-retest reliability of the Importance of Cues Questionnaire is also seen in the results. The top three cues across the age groups stayed wholly consistent in which cues were important (eg, facial expressions, body movements, sounds) and which cues were not (eg, infant's ability to remember or understand the pain experience).

Basic content validity of the two questions from the Infant Capabilities Questionnaire was also demonstrated by the results. It is a widely acknowledged fact that, other conditions being equal, the older an infant, the more able the infant is able to cognitively process the environment. Parental response trends on these questions (eg, more parents agreed that older infants, as opposed to younger infants, were able to remember and understand pain) clearly parallel this widely acknowledged fact. However, this systematic response trend makes speculations about test-retest reliability difficult. The following discussion utilizing these measures should be interpreted cautiously until research establishing the reliability and validity of these measures have been conducted.

As the infants increased in age, a progressively larger proportion of parents believed the infants to be capable of remembering and understanding pain. Forty-one per cent of parents believed two-month-olds could understand pain and this figure increased to $90 \%$ of the parents for 18-month-olds. Memory for pain was also perceived as transforming with age, but in a less substantial manner. Twenty-eight per cent of parents perceived two-month-old infants as capable of remembering the event, while $41 \%$ of parents attributed this capability to 18 -month-old infants. Parents tended to be more equally split between the three options with the younger infants. With the older infants, a larger proportion of parents were confident that the older children could remember pain.

\section{Making pain judgements: Importance of understanding and memory as judgement cues}

Contrary to our initial hypothesis, parental self-report suggests that attributions of infant memory and understanding are not crucial to attributions of infant pain. Parents were prepared to attribute relatively high levels of pain even to children whom they perceived as having a limited capacity to understand and 
remember pain. Thus, memory and understanding, features of an older child's and adult's experience of pain, were not construed as important cues in judging infant pain compared with more behavioural cues (eg, facial expressions, body movements and sounds). However, it is noteworthy that importance ratings for both the infant's capacity to understand and remember pain steadily increased with age. Despite wide acceptance that memory and understanding are important features of the adult pain experience, this sample of parents appreciated that the experience of pain does not require these mature capabilities. This is in opposition to published opinions whereby infant pain is distinguished from adult pain (by using such terms as elementary nocioception, inferred pain or probable pain) because of an infants' developing abilities to understand and remember a noxious experience $(19,47)$. It is acknowledged that the lack of relationship between pain ratings and beliefs about memory/understanding could be due to a lack of statistical power. However, given the coherent pattern of results (low importance ratings for 'understanding' and 'remembering' cues; no relationship between capability beliefs and pain ratings; no relationship between the importance rating of these cues and the pain ratings), it appears to the authors that beliefs about an infant's capability to remember or understand the pain experience does not significantly influence pain attributions.

Other caregivers have also characterized the infant pain experience as qualitatively different than that of older children and adults. Franck (41) reported that 40 of 76 nurses believed that infants feel pain differently than adults. Of the 35 nurses who provided a reason for this belief, 14 gave a cognitive explanation. Six believed that infants cannot anticipate pain, six believed that they could not comprehend pain and two believed that infant memory of pain was different.

In terms of the prioritizing of other cues, parents were quite consistent with past work in this area. The vast majority of studies evaluating which cues in the infant pain judgement context are important have been conducted with nurses. Across studies, vocalizations, body movements or posture, and facial expressions were consistently mentioned as important cues to nurses (9-17), suggesting a similar information collection process in pain assessment between nurses and parents.

Three recent reviews offer a survey of multidimensional measures for acute pain in full-term infants and the authors expressed the opinion that using multiple cues to judge infant pain serves to increase the accuracy of a pain judgement $(6,48,49)$. Parents, despite their lack of formal training, appear to be using multiple cues when assessing their pain judgements. This is evident not only by the consistently high importance ratings given to multiple cues (eg, facial activity, cry and body movement), but, also by the minimal difference in mean importance ratings for their top cues. Interestingly, the parents' top three cues are used as indicators on the vast majority of multidimensional measures in the published literature to date $(4,40,50-52)$.

\section{Conclusion}

The study did not address the infants' objective capacities to understand and remember pain. Although little is known about these capabilities, evidence is mounting for important and sometimes deleterious long-term consequences of uncontrolled pain in the neonate $(2,24,25,53)$.

The current work suggests that parents believe infants experience pain during routine immunizations. Health delivery practices increasingly provide for ambulatory and day surgery practices, shifting the onus for care of children to parents (54). Parents appear to be sensitive and sympathetic to infants' needs. They do not seem at risk of using the argument that an infant will not understand nor remember pain to justify withholding pain relief. Whether these sensitivities actually translate into more humane caregiving practices (increased pharmacological or behavioural management strategies) with their own children (parents judged infants that were not their own) in more realistic environments (parents judged pain in a closed room rather than a health care setting) needs to be examined. Furthermore, the sample of parents were highly educated as a group. Further work should explore the applicability of these findings with parents having less formal education.

Despite the central role parents have in caring for infants in pain when they are outside medical settings, little work has been done concerning how they make judgements of pain (55). This study adds to the sparse literature base regarding factors integral to a parent's judgement of infant pain.

FINANCIAL SUPPORT: This work was made possible by support from the Canadian Institutes of Health Research (Doctoral Awards to Ms Pillai Riddell and Ms Badali and a Senior Investigator Award to Dr Craig). The Michael Smith Foundation for Health Research also contributed to this project through Doctoral Awards to Ms Pillai Riddell and Ms Badali.

\section{REFERENCES}

1. Anand KS, Grunau RVE, Oberlander TF. Developmental character and long-term consequences of pain in infants and children. Child Adolesc Psychiatr Clin N Am 1997;6:703-24.

2. Grunau RVE. Long-term consequences of pain in human neonates. In: Anand KJS, Stevens BJ, McGrath PJ, eds. Pain in neonates, 2nd edn. Amsterdam: Elsevier Science, 2000:55-76.

3. Grunau RVE, Craig KD. Pain expression in neonates: Facial action and cry. Pain 1987;28:395-410.

4. Lawrence J, Alcock D, McGrath P, et al. The development of a tool to assess neonatal pain. Neonat Netw 1993;12:59-66.

5. Stevens B, Johnston C, Petryshen P, et al. Premature infant pain profile: Development and initial validation. Clin J Pain 1996;12:13-23.

6. Abu-Saad HH, Bours GJJ, Stevens B,Hamers JPH. Assessment of pain in the neonate. Semin Perinatol 1998;22:402-16.

7. Frank LS, Miaskowski C. Measurement of neonatal responses to painful stimuli: A research review. J Pain Symptom Manage 1997;14:343-78.

8. Craig KD. Emotions and psychobiology. In: Wall PD, Melzack R, eds. Textbook of pain, 4th edn. Edinburgh: Churchill-Livingstone, 1999:331-44.

9. Bradshaw C, Zeanah PD. Pediatric nurses' assessments of pain in children. J Pediatr Nurs 1986;1:314-9.

10. Pigeon HM, McGrath PJ, Lawrence J, MacMurray, SB. Nurses' perceptions of pain in the neonatal intensive care unit. J Pain Symptom Manage 1989;4:179-83.

11. Jones MA. Identifying signs that nurses interpret as indicating pain in newborns. Pediatr Nurs 1989;15:76-9.

12. Shapiro CR. Nurses' judgements of pain in term and preterm newborns. J Obstet Gynecol Neonatal Nurs 1993;22:41-6.

13. Fuller B, Thomson M, Conner DA, et al. Relationship of cues to assessed infant pain group. Clin Nurs Res 1996;5:43-66.

14. Fuller BF, Conner DA. Distribution of cues across assessed groups of infant pain. Clin Nurs Res 1996;5:167-84.

15. Howard VA, Thurber FW. The interpretation of infant pain: Physiological and behavioral indicators used by NICU nurses. J Pediatr Nurs 1998;13:164-74.

16. Hudson-Barr D, Duffey MA, Holditch-Davis D, Funk S, Frauman A. Pediatric nurses' use of behaviours to make medication administration decisions in infants recovering from surgery. Res Nurs Health 1998;21:3-13. 
17. Fuller BF, Neu M, Smith M, Vojir CP. Testing a model of the nursing assessment of infant pain. Clin Nurs Res 1999;8:69-83.

18. Derbyshire SWG. Locating the beginnings of pain. Bioethics 1999;13:1-31

19. Merskey H. Pain, consciousness and behaviour. Pain Res Manage 1997;2:118-22.

20. Vertosick FT. Why we hurt: The natural history of pain. San Diego: Harcourt, 2000.

21. Anand KJS, Hickey PR. Pain and its effects in the human neonate and fetus. N Engl J Med 1987;317:1321-9.

22. Grunau RVE, Whitfield M, Petrie JH. Pain sensitivity and temperament in extremely-low-birth-weight toddlers, and preterm and full-term controls. Pain 1994;58:341-6.

23. Grunau RVE, Whitfield M, Petrie JH, et al. Early pain experience, child and family factors, as precursors of somatization: A prospective study of extremely premature and full-term children. Pain 1994;56:353-9.

24. Taddio A, Goldbach M, Ipp M, et al. Effects of neonatal circumcision on pain responses during vaccination in boys. Lancet 1995;345:291-2.

25. Taddio A, Katz J, Ilersich AL, et al. Effect of neonatal circumcision on pain response during subsequent routine vaccination. Lancet 1997;349:599-603.

26. Anand KJS, Craig KD. Editorial: New perspectives on the definition of pain. Pain 1996;67:3-6.

27. Anand KJS, Hickey PR. Halothane-morphine compared with high dose sufentanil for anesthesia and postoperative analgesia in neonatal cardiac surgery. N Engl J Med 1992;326:1-9.

28. Fitzgerald M. Development of pain pathways and mechanisms. In: KJS Anand, PJ McGrath, eds. Handbook of Experimental Pharmacology: The pharmacology of pain. Berlin: Springer-Verlag, 1997:19-37.

29. Craig KD, Whitfield MF, Grunau RVE, et al. Pain in the preterm neonate: Behavioural and physiological indices. Pain 1993;52:297-9.

30. Damasio A. The feeling of what happens: Body and emotion in the making of consciousness. San Diego: Harcourt, 1999.

31. Lilley CM, Craig KD, Grunau RVE. The expression of pain in infants and toddlers: Developmental changes in facial action. Pain 1997;72:161-70.

32. Kazdin AE. Research design in clinical psychology. Boston: Allyn \& Bacon, 1998.

33. Flaherty SA. Pain Measurement tools for clinical practice and research. AANA J 1996;64:133-40.

34. Luria $\mathrm{R}$. The validity and reliability of the visual analogue mood scale. J Psychiatr Res 1975;12:379-84.

35. Joyce C, Zultshi DW, Hrubes V, et al. Comparison of fixed interval and visual analogue scales of rating chronic pain. E J Clin Pharmacol 1975;8:415-20.

36. Revill S, Robinson J, Rosen M, Hogg M. The reliability of a linear analogue for evaluating pain. Anaesthesia 1976;31:1191-8.
37. Melzack R Katz J. Pain measurement in persons in pain. In: Wall P, Melzack R, eds. The textbook of pain. Churchill Livingstone: Edinburgh, 1999:409-26.

38. Buchholz M, Karl HW, Pomietto M, Lynn A. Pain scores in infants: A modified infant pain scale versus visual analogue. J Pain Symptom Manage 1998;15:117-24

39. Fuller B, Thomson M, Conner DA, Scanlan J. Relationship of cues to assessed infant pain level. Clin Nurs Res 1996;5:43-66.

40. Taddio A, Nulman I, Koren BS, Stevens B, Koren G. A revised measure of acute pain in infants. J Pain Symptom Manage 1995; 10:456-63.

41. Franck LS. A national survey of the assessment and treatment of pain and agitation in the neonatal internsive care unit. J Obstet Gynecol Neonatal Nurs 1987;16:387-93.

42. Hadjistavropoulos HD, Craig KD, Grunau RE, et al. Judging pain in infants: Behavioral, contextual, and developmental determinants. Pain 1997;73:319-24

43. Collins SL, Moore AR, McQuay HJ. The visual analogue pain intensity scale: What is moderate pain in millimetres? Pain 1997;72:95-7.

44. Schechter NL, Allen DA. Physicians' attitudes toward pain in children. J Dev Behav Pediatr 1986;7:350-4.

45. McLaughlin CR, Hull JG, Edwards WH, et al. Neonatal pain: A comprehensive survey of attitudes and practices. J Pain Symptom Manage 1993;8:7-16.

46. Porter FL, Wolf CM, Gold J, et al. Pain and pain management in newborn infants: A survey of physicians and nurses. Pediatrics 1997; 100:626-32.

47. Derbyshire SWG. Comment on editorial by Anand \& Craig. Pain 1996;67:210-1

48. Franck LS, Greenberg CS, Stevens B. Pain assessment in infants and children. Pediatr Clin of North Am 2000;47:487-512.

49. van Dijk M. Commentary: Postoperative pain assessment in neonates and infants: State of the art. Pediatric Pain Letter 2001;5:37-8.

50. Hodgkinson K, Bear M, Thorn J, et al. Measuring pain in neonates: Evaluating an instrument and developing a common language. Aust J Adv Nurs 1994;12:17-9.

51. Horgan M, Choonara I. Measuring pain in neonates: An objective score. J Pediatr Nurs 1996;8:24-7.

52. Joyce BA, Schade JG, Keck JF, et al. Reliability and validity of preverbal pain assessment tools. Issues Compr Pediatr Nurs 1994;17:121-35.

53. Taddio A, Shah V, Gilbert-MacLeod C, Katz J. Conditioning and hyperalgesia in newborns exposed to repeated heel lances. JAMA 2002;288:857-61.

54. Bennett-Branson SM, Craig KD. Postoperative pain in children: Developmental and family influences on spontaneous coping strategies. Can J Behav Sci 1993;25:355-83.

55. Craig KD, Badali MA. On knowing an infant's pain. Pain Forum 1999;8:74-7. 


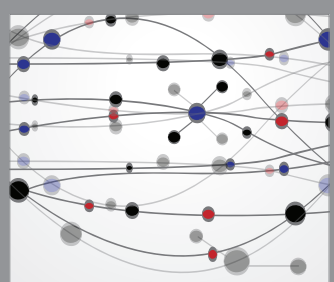

The Scientific World Journal
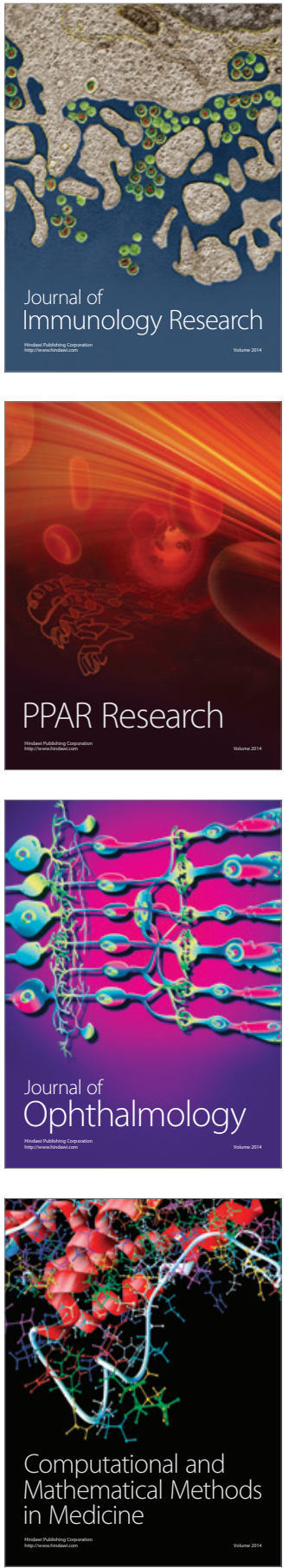

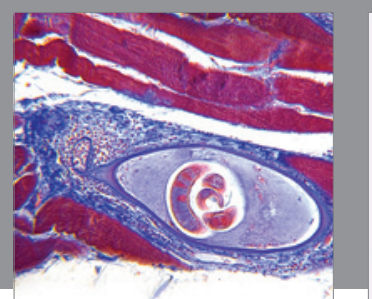

Gastroenterology Research and Practice

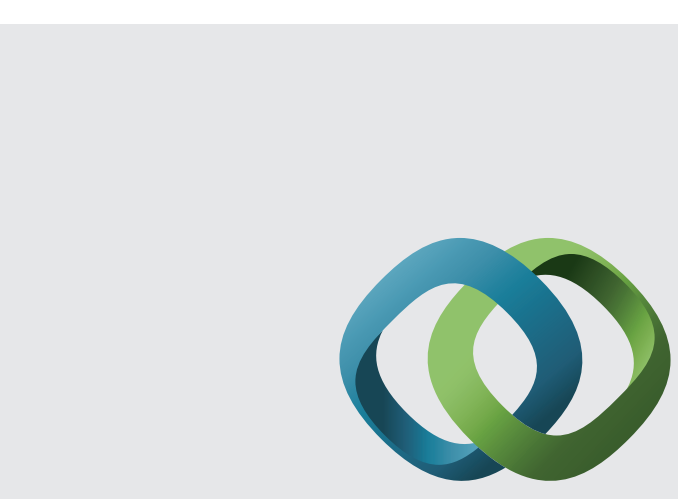

\section{Hindawi}

Submit your manuscripts at

http://www.hindawi.com
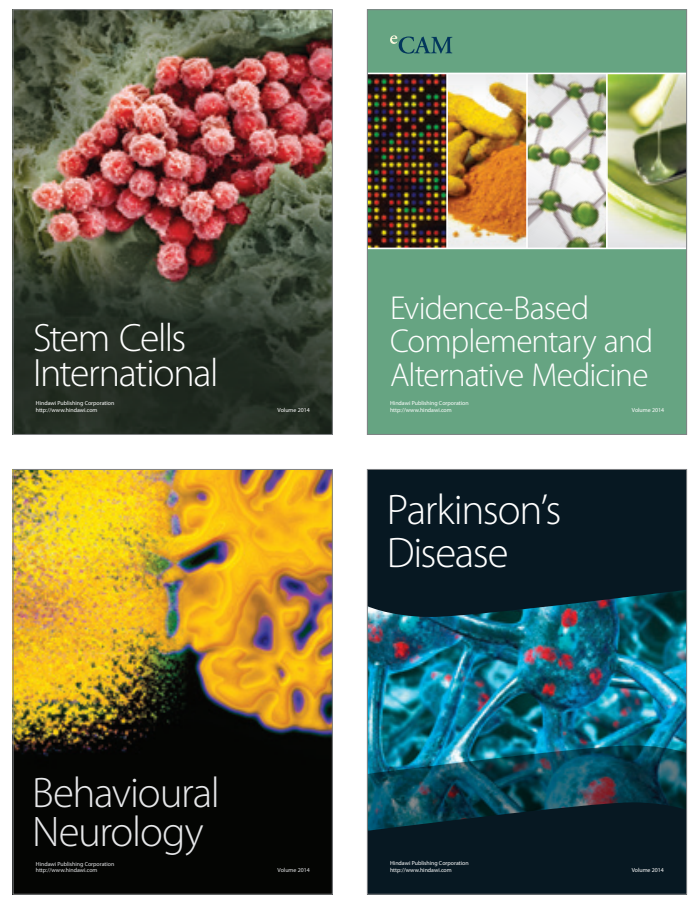
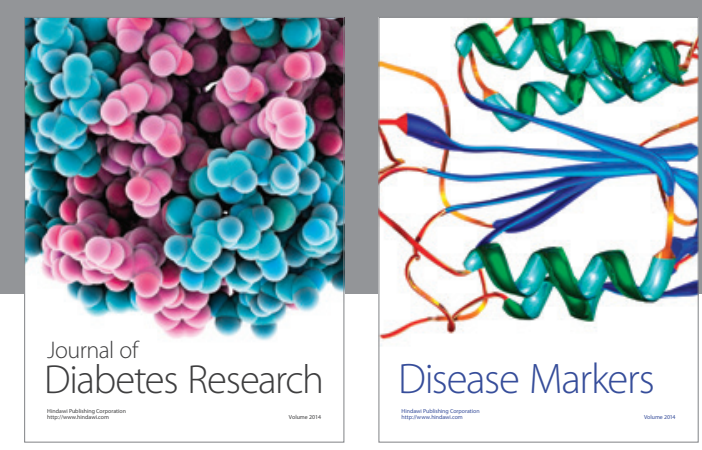

Disease Markers
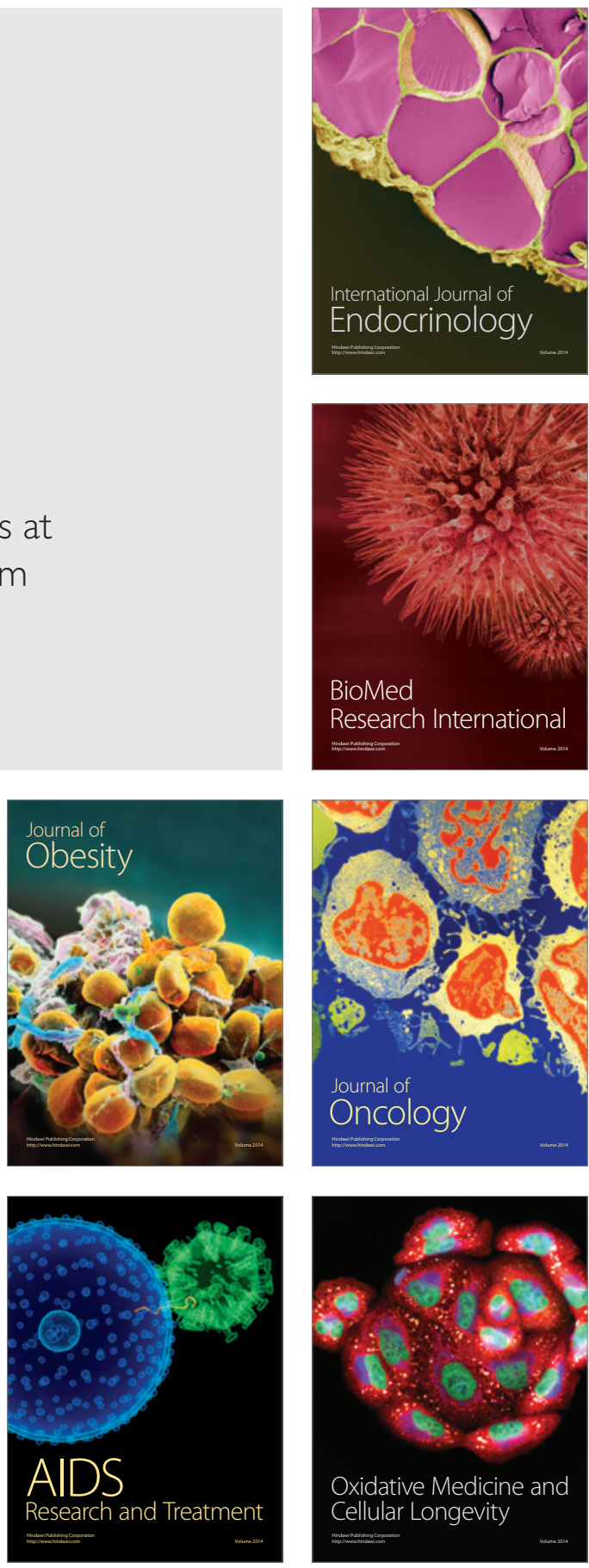